\title{
A importância do recrutamento e seleção interna: Um estudo de caso em uma Instituição Financeira de Economia Mista
}

\section{The importance of recruitment and internal selection: a case study in a financial institution of mixed economy.}

\author{
Fernanda Augusta de Oliveira Melo ${ }^{1}$ \\ Patrícia Nunes Costa Reis ${ }^{2}$ \\ Hyder Marcelo Araújo Lima ${ }^{2}$ \\ Edson dos Santos Ribeiro ${ }^{2}$ \\ Stifanie Paula da Silva ${ }^{3}$
}

Palavras-chave:

Recrutamento

Seleção

Processo

Planejamento

\section{Resumo:}

A era do conhecimento, em que o capital humano e suas capacidades são vistos como fatores competitivos no mercado de trabalho globalizado, tem forçado as empresas a buscarem novas formas de gestão objetivando melhorar o desempenho, alcançar melhores resultados e atingir a missão institucional para o pleno atendimento aos anseios dos seus consumidores. Assim, esta pesquisa visa discutir a importância do processo de Recrutamento e Seleção Interna na Instituição Financeira Banco do Brasil (BB), mediante a utilização de estudo de caso como método de investigação, visando analisar os resultados organizacionais esperados por essas instituições. Com intuito alcançar o objetivo proposto, foi realizada uma pesquisa de cunho descritivo e bibliográfico, visando analisar ou explicar um determinado problema à luz do referencial teórico existente. Dessa forma, conclui-se que a empresa usa, de forma correta, seu plano de carreira, dando a devida importância ao processo de recrutamento e seleção interna da instituição. Como hipótese, a fim de aprimorar o conhecimento dos gestores que atuam nesse processo de analise dos funcionários, a empresa poderia disponibilizar cursos específicos para seus gestores quando aprimorarão seus conhecimentos em planejar, recrutar e capacitar o indivíduo para adequá-lo no sistema organizacional da empresa.

\section{Abstract}

In the era of knowledge, human capital and skills are seen as competitive in the globalized labor market has forced companies to seek new forms of management in order to improve performance, achieve better results and achieve the institutional mission to the full meet the needs of its consumers. Thus, this research aims to discuss the importance of recruitment and selection process on Internal Financial Institution Bank of Brazil (BB), using case study as research method in order to analyze the organizational results expected by these institutions. To achieve the proposed objective a survey was conducted from a descriptive and bibliographical in order to analyze or explain a particular problem in light of existing theoretical framework. And to better support the research, we used a case study. Through this research, which analyzed the process of internal recruitment and selection of a financial institution, it was found that the company has a structured career plan. Thus we conclude that the company uses correctly your career plan, giving due importance in the process of internal recruitment and selection of the institution. As a hypothesis, in order to improve the knowledge of managers who work in this process of analysis of employees, the company could provide specific courses for its managers which will enhance their knowledge in planning, recruiting and training the individual to fit in the organizational system company.
Key words:

Recruitment

Selection

Process

Planning

Recebido em 09/2011

Aprovado em $12 / 2011$

Artigo

Original

Original

Paper 
Algumas organizações encontram dificuldades em suprir suas necessidades de capital

Atualmente, o mercado de trabalho, encontra-se bastante competitivo voltado para a qualidade total, onde o talento e o perfil profissional adequado para suprir as necessidades tornam-se uma tarefa determinante para o sucesso das organizações.

O recrutamento de pessoal constitui um processo que visa atrair candidatos diretamente nas fontes de recrutamento, sejam elas internas ou externas. As características da mãode-obra determinarão a escolha das fontes de recrutamento (TACHIZAWA, FERREIRA e FORTUNA, 2001).

As empresas vêem o processo de seleção de pessoal como peça chave para o sucesso do negócio. Evita-se gasto e tempo numa escolha inadequada (PEREIRA, PRIMI \& COBERO, 2000).

Neste cenário, o desenvolvimento de carreira constitui um fator motivacional utilizado pelas empresas e os processos de recrutamento e seleção interna representam uma das formas pela quais os colaboradores têm a perspectiva de crescimento profissional.

Entretanto, Spector (2002) evidencia ser um desafio constante para as empresas conseguirem candidatos às vagas disponíveis. $\mathrm{O}$ autor ressalta que contratar pessoas qualificadas, requer que a organização tenha um grande número de possíveis colaboradores, a fim de poder escolher entre eles.

Dessa forma, Chapman (1996), corrobora que, embora seja desgastante em termos de tempo, quanto maior o número de candidatos que você entrevistar, melhor o quadro que obterá da qualidade dos candidatos locais.

De acordo com Chiavenato (1997, p. 219), o recrutamento interno baseia-se em dados e informações relacionadas com os outros subsistemas, que incluem os resultados obtidos pelo candidato interno nos testes de seleção realizados quando o mesmo ingressou na organização, das avaliações de desempenho e programas de treinamento de que o candidato interno participou, planos de carreira, a fim de verificar a trajetória mais adequada ao ocupante do cargo e por fim, as condições de promoção do candidato interno, analisando-se se o mesmo está "no ponto" de ser promovido e se há um substituto preparado para seu lugar. humano. Tais necessidades, planejadas inadequadamente, poderão gerar sérios problemas, inclusive a desmotivação do colaborador. Cabe ao gestor de capital humano o papel decisivo no processo de recrutamento e seleção interna, definindo o colaborador adequado para o cargo, a fim de serem cumpridos tanto os objetivos organizacionais como os individuais.

Na busca do desenvolvimento, o processo de Recrutamento e Seleção Interna tem a finalidade não só de economia financeira para as instituições, mas também como peça chave para motivar, oportunizar a carreira profissional e agregar qualidade de mão-de-obra, aprimorando seus produtos ou serviços.

Diante do exposto, o objetivo desse trabalho visa discutir a importância do processo de Recrutamento e Seleção Interna na Instituição Financeira Banco do Brasil (BB), mediante a utilização de estudo de caso, como método de investigação visando analisar os resultados organizacionais esperados por essas instituições.

Com intuito de melhor conduzir o processo de recrutamento e seleção utilizou-se de dois critérios básicos de investigação: (i) quanto aos fins; e (ii) quanto aos meios.

O primeiro critério apoiou-se na pesquisa exploratória mediante revisão, análises documentais e bibliográficas, buscando sistematizar o assunto desenvolvido por outros autores de forma a atingir os objetivos propostos.

Quanto aos meios de investigação optouse pela pesquisa bibliográfica, onde conforme afirma Cervo, Bervian e da Silva (2007) esse tipo de pesquisa visa analisar ou explicar um determinado problema a luz do referencial teórico existente.

A fim de aprimorar o conhecimento dos gestores que atuam nesse processo de análise dos funcionários, a hipótese que sustentou a investigação foi "a oferta de cursos específicos para gestores aprimorarem seus conhecimentos, adequando-o ao sistema organizacional".

\section{Gestão de Pessoas}

As organizações passaram a buscar novas formas de gestão com o intuito de melhorar o desempenho, alcançar resultados e atingir a 
missão institucional para o pleno atendimento das necessidades dos seus consumidores, em função dos avanços ocorridos nas últimas décadas. Nota-se também, que o sucesso das organizações modernas depende, e muito, do investimento no capital humano, com a identificação, o aproveitamento e o desenvolvimento do capital intelectual.

Contemporaneamente, percebe-se que a Gestão de Pessoas (GP) passou a ser estratégica para o alcance de resultados, inclusive, como um diferencial competitivo para estas, já que as atitudes de um líder influem no desenvolvimento e crescimento da organização.

Para vencer as dificuldades encontradas em gerir atores organizacionais, as empresas desempenham tarefas de motivação e estímulo às competências e habilidades das pessoas, procurando capacitá-las para o cenário atual.

De acordo com Fischer, Dutra e Amorim (2010 apud PICCOLOTTO, VASSARI, DUTRA. p. 1), em um ambiente cada vez mais turbulento e competitivo, a adaptação contínua das organizações passou a ser uma questão de sobrevivência, e a velocidade desse processo, a condição necessária para agregar um diferencial competitivo. A pressão pela transformação organizacional passa a ser uma constante na vida das organizações e não mais algo episódico. Nesse contexto, a gestão de pessoas efetuada pela organização deve estimular, oferecer suporte e preparar artífices das mudanças e deve gerar lideranças que inspirem e facilitem a transformação contínua.

\section{Planejamento de Pessoal}

O planejamento de pessoal é uma ferramenta que permite às empresas programarem suas futuras vagas, criando um processo com metas e responsabilidades, que visam às qualificações para o cargo, requisição e análise do cargo mediante mercado de trabalho, evitando assim, uma possível demissão desnecessária por uma escolha indevida.

Pontes (2008, p.69) enfatiza que a não realização do planejamento de pessoal, principalmente para os níveis gerenciais, pode acarretar problemas sérios. Um deles é o de promover alguém internamente para o novo cargo, sem o devido desenvolvimento, o que levará a um prová- vel mau desempenho, e o prêmio acaba virando castigo, já que o promovido pode ser demitido. Com base nesse planejamento, a empresa deixará de atuar de forma aleatória de forma aleatória, criando uma estratégia de previsão das futuras vagas, evitando problemas sérios.

Chiavenato (2002, p. 230) esclarece que a descrição e análise de cargo é o levantamento dos aspectos intrínsecos (conteúdo dos cargos) e extrínsecos (requisitos que o cargo exige de seu ocupante - fatores de especificações) do cargo. Qualquer que seja o método de análise aplicado, o importante é a seleção das informações a respeito dos requisitos e das características que o ocupante do cargo deverá possuir afim de que o processo de seleção se concentre neles.

O planejamento de pessoas, para a área de gestão pessoas, uma reflexão sobre o processo planejado anteriormente, elaborando-se novas estratégias com o propósito de atingir as metas. Banov (2010, p. 17) destaca que, encontrar pessoas as quais possam preencher as vagas disponíveis na organização pode levar tempo e, muitas vezes, de acordo com a urgência, as escolhas podem ser precipitadas e inadequadas. [...] O planejamento de pessoal tem como objetivo fazer uma previsão de vagas futuras que serão abertas, permitindo ações da empresa antes desta abertura.

A empresa, com um planejamento de pessoal estruturado, programa de estratégias; consegue usar corretamente seu tempo; estabelece as regras; delega de forma eficaz as tarefas, responsabilidades e normas organizacionais; otimiza um plano de carreira com interesses alinhados ao plano organizacional; e, fazendo-o eficaz e eficiente.

Chiavenato (1999, p.27) define as pessoas como agentes pró-ativos e empreendedoras. São pessoas que gerem e fortalecem a inovação e que produzem, vendem, servem ao cliente, tomam decisões, lideram, motivam , comunicam, supervisionam e dirigem o negócio da empresa.

As organizações focalizadas na estratégia compreendem a importância de comprometer e alinhar efetivamente todos os colaboradores ao implantar um novo processo organizacional. Sem a implementação efetiva do processo, as organizações não alcançam seus interesses organizacionais e os de seus clientes internos e externos. 
Marras (2000, p. 253) entende a administração estratégica de recursos humanos (AERH) como a gestão que privilegia como objetivo fundamental, através de suas intervenções, a otimização dos resultados finais da empresa e da qualidade dos talentos que a compõe.

O maior mérito do Planejamento estratégico organizacional está no alinhamento corporativo que o processo conduz na empresa, na sua capacidade de transformar intenções estratégicas em ações efetivas. O Planejamento estratégico deve conjugar a intenção da mudança, as ações tempestivas e alinhadas a monitoração constante.

\section{Processo de Recrutamento Interno}

As organizações possuem uma própria cultura e o processo de recrutamento e seleção exercem um papel de fundamental importância de suprir essas necessidades, visando à cultura e as normas da empresa.

O Processo de Recrutamento consiste em um conjunto de procedimentos que visa atrair candidatos potencialmente qualificados e capazes para ocupar cargo definidos nas empresas, ou seja, é basicamente, um sistema de informação que divulgará e ofertará ao mercado de recursos humanos oportunidades variadas de emprego.

$\mathrm{O}$ processo de recrutamento divide-se em várias etapas, e começa com a emissão da requisição de candidatos: $O$ órgão de recrutamento (staff) é o que escolhe os meios, e estes são relacionados em três processos; os processos de recrutamento interno (promoção ou transferência de pessoas), processos de recrutamento externo (candidatos externos a organização, busca no mercado de trabalho) ou processos mistos (candidatos da própria empresa e no mercado externo), no sentido de obter as maiores vantagens no processo, impetrando os melhores candidatos, o capital humano da organização.

Chiavenato (2009, p.105) argumenta que a tarefa do recrutamento é a de atrair com seletividade, mediante técnicas de divulgação para candidatos que possuam os requisitos mínimos do cargo a ser preenchido, enquanto a tarefa da seleção é a de escolher e filtrar, entre os candidatos recrutados, aqueles que tenham maiores probabilidades de se ajustar aos cargos vagos.
Dessa forma, o processo de recrutamento compreende procedimentos que visam atrair o elemento humano potencialmente qualificado para suprir as necessidades da empresa.

Banov (2010, p. 38) enfatiza que o recrutamento tem tido um valor mais elevado se comparado com épocas anteriores, em função de um grande número de candidatos para ocupação das vagas em aberto, o que faz o recrutamento cada vez mais estratégico para encontrar candidatos que atendam às necessidades das vagas.

Neste cenário, o processo de recrutamento vem crescendo cada vez mais visando atrair candidatos nas fontes de recrutamentos identificadas e localizadas no mercado de recursos humanos. Para ser eficaz, o recrutamento deve atrair um contingente de candidatos suficientes para abastecer adequadamente o processo de seleção que vem logo a seguir. A função do recrutamento é a de suprir a seleção de pessoal com matéria-prima básica (candidatos) para seu funcionamento adequado (CHIAVENATO, 2009, p. 68).

Diante do exposto, existe uma lacuna que deve ser preenchida, e o processo de recrutamento e seleção tem a função de suprir essa lacuna com o perfil adequado. $\mathrm{O}$ processo de mudança é sempre complexo, pois requer muito planejamento e aplicação de novas estratégias.

Muitas organizações, antes de contratar ou recrutar candidatos externos, fazem uma pesquisa interna na busca do profissional capacitado para preenchimento da vaga disponível, dessa forma, oportunizando a promoção aos seus colaboradores. Esse processo de recrutamento interno incentiva uma competição sadia entre os funcionários, os mesmos procuram dedicar-se mais, na expectativa de uma possível elevação de cargo e salário. A seleção interna torna-se viável para a organização, pois o processo se torna mais rápido e custo com essas contratações apresentam valor mínimo.

Banov (2010, p.40) esclarece que o recrutamento interno tem como vantagem: ser econômico, pelo fato de a divulgação ser feita dentro da própria empresa; logo, devido ao fato de os candidatos serem da empresa e estarem adequados à cultura organizacional, o processo torna-se mais rápido e aponta uma relação positiva entre empregado e empresa, já que esta, ao 
fazer o recrutamento interno, se mostra dando oportunidades a seu público interno.

Analisando esse contexto, as organizações possuem o histórico dos funcionários, pois os mesmos são acompanhados dentro do departamento em que trabalham. Dessa forma, o processo de recrutamento deve ser empregado com cautela, evitando conflitos de interesses entre os funcionários. A motivação é essencial aos mesmos, assim, estarão sempre se aprimorando e tornando-se capacitados para exercer diversas funções.

Salienta-seque o processo de Recrutamento e Seleção Interna propicia não só a economia financeira para as instituições, mas também, oportunizar o avanço na carreira profissional agregando qualidade à mão de obra, aprimorando produtos e serviços. Com os colaboradores almejando se aprimorar, as organizações estão investindo em pessoas, pois estão descobrindo que não são feitas somente de máquinas e equipamentos e sim de um capital humano primordial para seu desenvolvimento organizacional. Por mais que se tenha avanço tecnológico, jamais poderemos substituir o elemento humano que possui criatividade, capacidade para o aprendizado e vontade de vencer.

França (2009, p. 87) categoriza que - em virtude das constantes modificações macroambientais, competição por nichos e segmentos de mercado, maior competição interna por ascensão na carreira - é um consenso nas organizações a importância do treinamento em todos os níveis empresariais. Pessoas preparadas produzem melhor e se sentem mais autoconfiantes. Por outro lado, aqueles que não possuem um preparo adequado ao cargo estão mais propensos à tomada de decisão incorreta e, frequentemente, culpam terceiros por sua falta.

Assim, o processo de recrutamento interno deixa de ser somente baseado na experiência e na capacidade técnica dos candidatos. Pelo fato de as organizações estarem cada vez valorizando o ser humano, ou seja, estão avaliando também seu potencial emocional e intelectual. É imprescindível que cada candidato saiba trabalhar em grupo, tenha espírito de liderança, carisma, comunicabilidade e equilíbrio emocional para um bom desempenho profissional, associado ao conhecimento administrativo e técnico.
Torna-se imperioso o recrutamento e elaboração das diretrizes e políticas de planejamento, descrevendo os propósitos e objetivos do empregador no recrutamento, com intuito de delegar autoridade e responsabilidade apropriadas à função. França (2009, p.33), por exemplo, esclarece que a política de aproveitamento e mudança de pessoal interno envolve um conjunto de regras e a conjugação de objetos. $\mathrm{O}$ recrutamento interno fundamenta-se na valorização dos recursos humanos já existentes na empresa, criando espaços para o crescimento e a realização pessoal. Todo esse processo resulta, então, inevitavelmente, em melhor desempenho da mão de obra e da empresa como um todo.

O processo de recrutamento é a ocasião em que a empresa deve ter maturidade e boas técnicas e instrumentos de gerenciamento para identificar desvios e redirecionar ações estratégicas para atingir os resultados.

\subsection{Relação Interna: vantagens e des- vantagens do recrutamento}

A Empresa procura preencher a vaga através do remanejamento de seus empregados, transferência de pessoal, promoções de pessoal, transferência com promoções de pessoal, programas de desenvolvimento de pessoal, planos de encarreiramento (carreira) de pessoal.

Banov (2010, p.19) afirma que algumas substituições podem ser previstas, como a promoção- quando a empresa tem um plano de carreira- a transferência, a aposentadoria, a licença-maternidade, o serviço militar, o término de estágios e a rotatividade. É possível fazer um planejamento dessas substituições verificando as vagas que surgirão num determinado período (que pode ser mensal, bimestral, semestral, anual, conforme as necessidades da organização).

Esse processo de recrutamento interno, de certa forma, incentiva uma competição sadia entre os funcionários. Os mesmos procuram dedicar-se cada vez mais, na expectativa de uma possível elevação de cargo e salário. A seleção interna torna-se mais viável para a organização, pois o custo com essas contratações acaba sendo praticamente mínimo. Por outro lado, já se sabe do histórico do funcionário, pois o mesmo já vem sendo acompanhado dentro do departamento em que trabalha. 
Para Chiavenato (2009), o recrutamento interno motiva e, uma vez que estimula os colaboradores e os reconhece por seus esforços por uma nova vaga ou remanejamento, apresenta três características fundamentais:

- Promoção: movimentação vertical

- Transferência: movimentação horizontal
- Transferência com promoção: movimentação diagonal

Apesar de este ser um bom meio de recrutamento, o autor destaca as vantagens e desvantagens do recrutamento interno conforme demonstrado na Tabela 1.

Tabela 1 - Vantagens e desvantagens do recrutamento interno.

\begin{tabular}{|c|c|c|}
\hline & Vantagens & Desvantagens \\
\hline \multirow{7}{*}{ 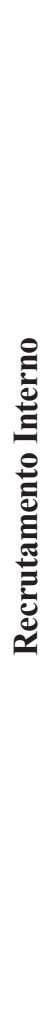 } & Mais rápido e econômico & Gerar conflitos de interesse \\
\hline & Maior índice de validade e de segurança & $\begin{array}{l}\text { Se administrado incorretamente pode Situações } \\
\text { de incompetência }\end{array}$ \\
\hline & Fonte de motivação para os empregados & $\begin{array}{l}\text { Quando efetuado continuamente pode levar } \\
\text { os empregados a uma progressiva limitação as } \\
\text { políticas e diretrizes da organização }\end{array}$ \\
\hline & $\begin{array}{l}\text { Aproveitamento dos investimentos da empresa } \\
\text { em treinamento de pessoal }\end{array}$ & $\begin{array}{l}\text { Não pode ser feito em termos globais dentro da } \\
\text { organização }\end{array}$ \\
\hline & $\begin{array}{l}\text { Desenvolver espírito de competição entre o } \\
\text { pessoal. }\end{array}$ & $\begin{array}{l}\text { As exigências de que os novos empregados tenham } \\
\text { condições de potencial de desenvolvimento para } \\
\text { poderem ser promovidos }\end{array}$ \\
\hline & $\begin{array}{l}\text { Renova e enriquece os recursos humanos da } \\
\text { organização. }\end{array}$ & Pode gerar conflitos de interesses. \\
\hline & $\begin{array}{l}\text { Aproveita os investimentos em preparação e o } \\
\text { desenvolvimento de pessoal efetuado por outras } \\
\text { empresas ou pelos próprios candidatos. }\end{array}$ & $\begin{array}{l}\text { Demora um tempo maior de planejamento e } \\
\text { desenvolvimento. }\end{array}$ \\
\hline
\end{tabular}

Fonte: elaborada pelos autores

Assim, de acordo com as vantagens e desvantagens dos recrutamentos interno e externo, um recurso eclético tem sido preferido pela maioria das empresas: o recrutamento misto, que aborda tanto fontes internas como fontes externas de recursos humanos.

Para França (2009, p.30 apud FLIPPO, 1961) um bom lugar para se trabalhar terá maior visibilidade e provavelmente maior número de candidatos. No entanto, é necessário planejar e organizar esforços para estimular e atrair novos talentos.
Além disso, como sistemas abertos, as organizações caracterizam-se pela rotatividade de pessoal, cujas causas podem ser internas, externas e mistas, mas que sempre impõem custos primários e secundários à organização. $\mathrm{O}$ absenteísmo, que é causado pela falta de capacidade profissional ou pela falta de motivação para o trabalho, constitui outro fator de incerteza e de imprevisibilidade, para as organizações. Toledo (1977) afirma que o recrutamento consiste na série de atividades que trata dos estudos e contatos com o mercado de mão de obra, assim como, a primeira convocação de candidatos. 


\section{Processo de Seleção de Pessoas}

O processo de seleção de pessoas é uma triagem que permite apenas a alguns candidatos ingressar na empresa: aquelas que possuam o perfil e características mais adequadas para atender as exigências da organização.

Marras (2000) define seleção como sendo uma atividade de responsabilidade do sistema de recursos humanos que tem por finalidade escolher, sob metodologia específica, candidatos a emprego recebidos pelo recrutamento para atendimento das necessidades internas da empresa.

Chiavenato (2009, p. 106) define seleção de recursos humanos como a escolha do homem certo para o cargo certo, ou, mais amplamente, entre os candidatos recrutados, aqueles mais adequados aos cargos existentes na organização, visando manter ou aumentar a eficiências e o desempenho do pessoal, bem como a eficácia da organização, ou seja, o processo de seleção visa resolver dois problemas básicos nas empresas: a adequação do homem ao cargo e a eficiência do homem no cargo.

Banov (2010, p.53) chama a atenção para o fato de que se as pessoas são diferentes e as empresas também, buscar a pessoa certa para o lugar certo é o objetivo básico do processo de Seleção de Pessoal. [...] As etapas completas de um processo de seleção são: análise de currículo, entrevista, aplicação de testes, dinâmicas de grupo e exame médico específico.

Neste sentido, o planejamento do processo de Seleção profissional torna-se fundamental para o sucesso da organização, visando à gestão de um processo criterioso, com a função de obter o profissional adequado.

Retornando a Chiavenato (2009, p.29), este justifica que o planejamento de recursos humanos representa um processo de decisão a respeito dos recursos necessários para atingir os objetivos organizacionais dentro de um determinado período de tempo. Trata-se de antecipar a força de trabalho e os talentos humanos necessários para a realização de ação organizacional futura.

Visando obter os melhores candidatos, as empresas atualmente ainda encontram dificuldades no método de administrar pessoas. Para ultrapassar essas dificuldades, as pessoas que fazem parte dos recursos humanos executam tarefas para desenvolver as competências e habilidades das pessoas, procurando capacitálas para as rápidas e intensas mudanças que ocorrem no mercado de trabalho.

Da mesma forma que Chiavenato, França (2009, p. 29) enfatiza que o Recrutamento e a Seleção devem ser integrados à estratégia de negócios da empresa. Se a empresa está necessitando passar por mudanças ou renovações, ela deverá buscar e atrair pessoas por mudanças ou por renovações, ela deverá buscar e atrair pessoas com esse potencial.

\section{Metodologia}

Para a classificação desta pesquisa, tomase como base a taxionomia apresentada por VERGARA (1997), que utiliza dois critérios básicos: quanto aos fins e quanto aos meios.

Quanto aos fins utilizar-se-á o critério de pesquisa exploratória, que se apoia em revisão, análises documentais e bibliográficas, buscando sistematizar o assunto desenvolvido por outros autores de forma a atingir os objetivos propostos.

Quanto aos meios de investigação optouse pela pesquisa bibliográfica, em que conforme afirma Cervo, Bervian e da Silva (2007) esse tipo de pesquisa visa analisar ou explicar um determinado problema a luz do referencial teórico existente.

\subsection{Estudo de caso: Instituição Financeira Banco do Brasil (BB)}

\subsubsection{Caracterização da empresa}

O Banco do Brasil S.A. (BB) é uma Iinstituição Financeira brasileira, constituída na forma de sociedade de economia mista, com participação da União brasileira em 68,7\% das ações. O BB foi o primeiro banco a operar no País e, hoje, é a maior e mais antiga instituição financeira do Brasil. Acumulando ao longo de sua história atributos de confiança, segurança, modernidade e credibilidade. Com sólida função social e com competência para lidar com os negócios financeiros, a instituição financeira demonstrou que é possível ser uma empresa lucrativa sem perder o núcleo de valores - o que sempre a diferenciou da concorrência. 
Como um dos principais agentes do desenvolvimento econômico e social do país, o BB impulsiona a economia e o desenvolvimento, atuando de forma responsável para promover a inclusão social, por meio da geração de trabalho e renda.

Para a Instituição Financeira BB ser coerente com o discurso de responsabilidade socioambiental adotado, é necessário que os processos de negócio e de apoio sejam permeados com a visão de sustentabilidade, ou seja, que além da eficácia de natureza econômica também seja buscada a geração de valores sociais e ambientais. Visando esse discurso, a empresa possui iniciativas que tangibilizam essas políticas, como os programas Qualidade de Vida no Trabalho, Programa de Reconhecimento dos Funcionários, Crédito Responsável, Programa de Eco eficiência entre outros são exemplos de do banco.

Como uma empresa competitiva, rentável e de economia mista, o BB possui a missão promover o desenvolvimento sustentável do Brasil e cumprir sua função pública com eficiência, seguindo Valores de Ética e transparência; Compromisso com o desenvolvimento das comunidades e do País; Responsabilidade socioambiental; Respeito ao consumidor; Excelência e especialização no relacionamento com o cliente; Gestão participativa, decisão colegiada e trabalho em equipe; Ascensão profissional baseada no mérito; Marca como diferencial competitivo; Proatividade na gestão de riscos; Comprometimento com solidez, rentabilidade, eficiência e inovação; Respeito à diversidade; Compromisso com os acionistas e a sociedade.

No BB existem dois tipos de seleção de funcionários: externo e interno. $\mathrm{O}$ interno se consiste de avaliações para ingressos de novos funcionários; e o interno, na utilização de um banco de dados que identifica os candidatos mais qualificados a preencherem cargos vagos. O objetivo da instituição financeira é valorizar seus funcionários e alinhar as promoções à forma de encarreiramento profissional. A estratégia de remuneração incentiva o funcionário a investir em sua formação profissional, além de remunerar, de maneira diferenciada, aqueles que reúnem requisitos importantes para empresa.

\subsubsection{Descrição dos cargos e a rela- ção com recrutamento e seleção interna}

Através do recrutamento e seleção interna, os colaboradores são selecionados para ocupar um determinado cargo e, em função do mesmo, serão designadas suas competências, de acordo com cada setor, visando às políticas e à cultura da empresa.

O BB possui um diferencial de mercado criado para minimizar a dificuldade de provimento de cargos diretivos ou gerenciais e técnicos especializados em praças de maior competitividade e custo de vida.

Banov (2010, p. 5) esclarece que a coleta de dados antecede ao recrutamento e à seleção de pessoal sobre a cultura organizacional, a estrutura organizacional, a visão, os valores da organização e análise do mercado de trabalho, que direcionarão as políticas de recrutamento e de seleção de pessoal.

A descrição de cargos estabelece os requisitos para desempenhar os cargos em função das competências exigidas pela instituição.

A descrição dos cargos da Instituição Financeira, segundo o estudo realizado por Mucha, 2003, e pesquisa realizada no site Ministério do Trabalho e Emprego segundo Tabela 2. 


\begin{tabular}{|c|c|}
\hline Cargos & Descrição \\
\hline Gerente Geral & $\begin{array}{l}\text { Exerce a gerência de agência bancária, planejando, organizando } \\
\text { e controlando os diversos programas propostos e avaliando os } \\
\text { resultados alcançados, para assegurar sua perfeita execução e, em } \\
\text { consequência, melhores resultados para sua agência: responde pela } \\
\text { qualidade dos serviços prestados, identificando causas de problemas } \\
\text { e orientando tecnicamente sua equipe na resolução dos mesmos, } \\
\text { para garantir melhor atendimento aos clientes; acompanha posição } \\
\text { contábil diária através de relatórios, coordena o expediente da agên- } \\
\text { cia, atua junto aos demais gerentes, identificando novos clientes } \\
\text { e incrementando planos de vendas, para atingir objetivos estabe- } \\
\text { lecidos pela diretoria; mantém atualizados seus conhecimentos, } \\
\text { realizando a leitura constante de publicações técnicas e/ou gerais, } \\
\text { para assegurar a regularidade das operações desenvolvidas; realiza } \\
\text { o atendimento ao cliente (pessoa física ou jurídica), a manutenção, } \\
\text { seleção e ampliação da base de negócios/clientes, primando pela } \\
\text { excelência dos serviços prestados, para conseguir máxima captção } \\
\text { de recursos financeiros; responde pela conservação do patrimônio, } \\
\text { verificando o estado de conservação das instalações físicas e equi- } \\
\text { pamentos, para permitir sua perfeita preservação. }\end{array}$ \\
\hline Gerente de contas & $\begin{array}{l}\text { Responsável exclusivamente pelo gerenciamento de carteiras. Sua } \\
\text { principal função será estreitar o relacionamento com clientes e con- } \\
\text { tribuir para a expansão da base. Equilíbrio gerado pelo estágio de } \\
\text { relacionamento do cliente; ferramenta de avaliação de carteiras, que } \\
\text { estará adequada ao Modelo de Relacionamento; adequação das car- } \\
\text { teiras à capacidade de atendimento do gerente de contas; e alteração } \\
\text { das faixas de renda. }\end{array}$ \\
\hline Gerente de expediente & $\begin{array}{l}\text { Responsável pelos Grupos Negociais. Sua atuação será fundamental } \\
\text { para a migração do atendimento dos clientes massificados para ou- } \\
\text { tros canais de atendimento (externos ao ambiente da agência), como } \\
\text { a Central de Atendimento, a Internet, o terminal de autoatendimento. } \\
\text { Para auxiliar na realização de negócios dentro dos Grupos, será acio- } \\
\text { nado o assistente de negócios. }\end{array}$ \\
\hline Gerente de administração & $\begin{array}{l}\text { Gerenciar o trabalho de transferência de transações de clientes mas- } \\
\text { sificados para os canais automatizados. Controle a disponibilidade e } \\
\text { adequação dos pontos de atendimento segundo as necessidades da } \\
\text { agência e dos clientes }\end{array}$ \\
\hline Escriturário & $\begin{array}{l}\text { Responsável por garantir a satisfação dos clientes e a migração para } \\
\text { os canais automatizados. Direcionar o atendimento massificado PF } \\
\text { e PJ, para o segmento administrativo e para o autoatendimento }\end{array}$ \\
\hline Assistente de negócios & $\begin{array}{l}\text { Responsável por apoiar os gerentes de contas e gerentes de expedien- } \\
\text { te na realização de negócios e na condução de processos operacio- } \\
\text { nais. A sua atuação fortalecerá o atendimento e relacionamento com } \\
\text { os clientes. Serão acionados para as carteiras e grupos negociais. }\end{array}$ \\
\hline
\end{tabular}

Fonte: elaborada pelos autores

Diante das mudanças em função da globalização econômica, evolução das comunicações, desenvolvimento tecnológico e competitividade- de acordo com a Associação Nacional dos Funcionários do Banco do Brasil (ANABB)- o BB implantou o Plano de Carreira e Remuneração (PCR), em substituição ao atual Plano de Cargos e Salários (PCS).
O novo Plano foi elaborado com base em premissas alinhadas à Estratégia Corporativa e à Política de Governança Corporativa da instituição, no que diz respeito à ascensão baseada no mérito, competência, ética e transparência. Com o novo Plano de Carreira e Remuneração (PCR), houve mudanças de nomenclaturas de alguns cargos citados por Mucha (2003). 
- Gerente de contas - Gerente de relacionamento

- Gerente de expediente - Gerente de Serviços

- Gerente de administração - Gerente de Negócios

O Programa considera as competências profissionais do funcionário, visando à sua movimentação na empresa, além de propiciar o desenvolvimento de competências a partir da sinalização dos caminhos a serem percorridos para ascensão às diversas funções na empresa.

As Descrições dos Cargos por Segmentos são compostas pelos seguintes Módulos:

- Pessoas Físicas: conjunto das carteiras formadas e/ou em formação de clientes pessoas físicas;

- Pessoas Jurídicas: conjunto das carteiras formadas e/ou em formação de clientes pessoas jurídicas;

- Governo: carteira formada de clientes do Setor Público;

- Atendimento: conjunto dos grupos formados e/ou em formação de clientes pessoas físicas e pessoas jurídicas. Além disso, responde pela prestação de serviços e atendimento de consumidores bancários; e

- Conveniência: corresponde ao ambiente da agência voltado para o relacionamento com clientes e oferta ativa de produtos e serviços e para a realização de transações bancárias por meio de canais automatizados.

Os Módulos possuem as seguintes atribuições:

- Módulos Pessoas Físicas, Pessoas Jurídicas e Governo: planejar e desenvolver ações para cumprimento das metas estabelecidas; coletar, analisar e registrar informações necessárias à realização de negócios; conduzir o relacionamento com clientes na forma definida; realizar negócios com clientes; prestar consultoria e/ou assessoria financeira; operacionalizar as atividades complementares ao negócio; conduzir operações de crédito nas fases condução e cobrança; efetuar cobrança de dívidas; e avaliar os resultados dos negócios efetuados.

- Módulo Atendimento: planejar e organizar o atendimento a clientes e consumidores bancários; monitorar a ambiência da área de atendimento; planejar e desenvolver ações para cumprimento das metas estabelecidas; coletar, analisar e registrar informações necessárias à realização de negócios; conduzir o relacionamento com clientes na forma definida; prestar atendimento a clientes e a consumidores bancários; orientar clientes sobre produtos e serviços; realizar negócios com clientes; operacionalizar as atividades complementares ao negócio; conduzir operações de crédito nas fases condução e cobrança; efetuar cobrança de dívidas; e avaliar os resultados dos negócios efetuados.

- Módulo Conveniência: orientar o fluxo de atendimento durante o expediente da agência; orientar os clientes no uso de canais automatizados; orientar clientes e consumidores bancários sobre produtos e serviços; conduzir as atividades relativas à disponibilidade de material promocional no expediente da agência; monitorar a disponibilidade de terminais de autoatendimento.

Diante do exposto, o Segmento Relacionamento é responsável pela implementação das estratégias de relacionamento com os clientes. Prestação de serviços e atendimento de consumidores bancários e pela condução e/ou execução de atividades complementares ao negócio. Ao Segmento compete: identificar oportunidades negociais; implementar as estratégias de relacionamento definidas; conduzir atividades complementares ao negócio; gerir os negócios realizados com clientes; gerir a prestação de serviços destinados a consumidores bancários; gerir o atendimento da agência; cumprir as metas estabelecidas; e acompanhar os resultados dos negócios. 
Os Segmentos são responsáveis pelas competências relativas às operações de suporte ao negócio e pela condução dos processos internos da agência. Ao Segmento compete: gerir as operações de suporte ao negócio; gerir os processos internos da agência; gerir os recursos materiais, tecnológicos e financeiros da agência; e acompanhar o orçamento e o Acordo de Trabalho da agência.

O Segmento é composto pelos seguintes Módulos:

- Pagamentos e Recebimentos: corresponde ao conjunto de atividades relativas ao processamento de papéis de caixa decorrentes de pagamentos e recebimentos;

- Tesouraria: corresponde ao conjunto de atividades relativas à guarda, movimentação, suprimento e gestão de numerário e de outros valores; e;

- Apoio Administrativo: corresponde ao conjunto de atividades relativas aos processos internos da agência.

Os Módulos possuem as seguintes atribuições:

- Módulo Pagamentos e Recebimentos: efetuar pagamentos e recebimentos aos clientes e consumidores bancários; efetuar processamento de papéis de caixa e de compensação de cheques e outros documentos.

- Módulo Tesouraria: conduzir as atividades relativas ao gerenciamento do fluxo de numerário da agência; efetuar a guarda de valores da agência; conduzir as atividades relativas à custódia de cheques; e efetuar o suprimento de numerário e de consumíveis.

- Módulo Apoio Administrativo: conduzir serviços de cobrança e demais convênios; executar atividades de escrituração, conciliação contábil e balancetes; realizar e controlar as despesas administrativas; executar serviços de funcionalismo; providenciar o atendimento das demandas originárias dos poderes públicos; controlar os recursos materiais e tecnológicos; conduzir as atividades de administração predial; acompanhar os serviços executados pelas empresas prestadoras de serviços na agência; conduzir as atividades relacionadas à manutenção preventiva e corretiva dos equipamentos da agência; executar atividades operacionais relativas a falhas em serviços, fraudes e processos administrativos; executar atividades relativas à comunicação interna; prestar apoio administrativo ao Comitê de Administração da agência; e controlar a execução orçamentária e o Acordo de Trabalho

Estrutura organizacional pelos cargos em tipologia Hierárquica ao Gerente de agência.

- Segmento Relacionamento: Gerente de contas; Gerente de contas governo; Gerente de expediente; Assistente de negócios; e Escriturário.

- Segmento de Serviços: Gerente de administração; Gerente de expediente; Caixa executivo; e Escriturário.

\subsubsection{Perfil dos funcionários}

Em visão da motivação, a Instituição BB favorece a aquisição de conhecimentos importantes para sua formação profissional como bancário; orientando o seu desenvolvimento profissional, apontando quais são os conhecimentos fundamentais para as funções que você deseja ocupar.

Os perfis são estabelecidos com objetivo a identificação de funcionários com potencial para assumirem funções do segmento em relação às competências profissionais ao exercício das funções.

No ano de 2006, como aponta o site da Federação Nacional dos Bancos (FENABAN) , a instituição ofereceu 26 mil vagas para Certificação nos seguintes temas: Gestão de Pessoas, Gestão de Finanças, Gestão de Marketing, Responsabilidade Socioambiental, Gestão do Crédito, Comércio Internacional e Teoria Geral da Administração - TGA.

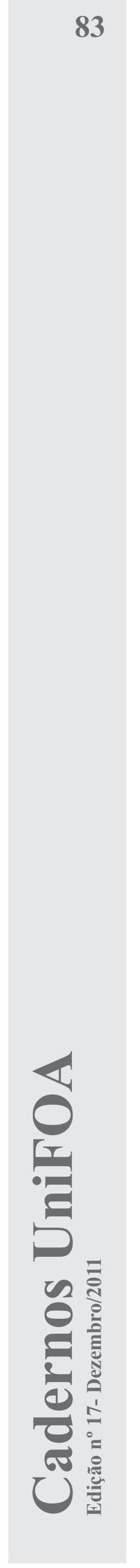


- Planejamento;

- Iniciativa e Dinamismo;

- Atuar com dinamismo.

Ao Segmento Relacionamento compete apresentar:

- Comprometimento;

- Comunicação;

- Capacidade de análise.

Ao Segmento de Serviços compete apresentar:

- Relacionamento interpessoal;

- Visão sistêmica;

- Planejamento;

- Dinamismo;

- Comprometimento

\subsubsection{Disponibilização da vaga}

As medidas de disponibilização das vagas são elaboradas a partir de propostas da Gestão de Pessoas e Responsabilidade Socioambiental da instituição, que num esforço conjunto com diversas diretorias, buscam traduzir com fidelidade os anseios dos funcionários da Rede, constituindo efetivamente em facilitadores de seu trabalho.

A instituição possui um Sistema operacional on-line de Serviços internos, onde se administra as tarefas da instituição. A Gestão de Pessoas disponibiliza as vagas pelo sistema operacional da instituição. Sistema este que sintetiza um aplicativo de Gerenciamento de Talentos e oportunidades que se destina a identificar talentos e evidenciar oportunidades de apoio aos processos seletivos, pois o aplicativo é composto por dois módulos: a) talentos; b) oportunidades (cargos).

É fundamental a participação dos administradores na divulgação e explicação das ações para sua equipe, e que cada administrador tome para si a responsabilidade pela condução desse processo. Para isso, é realizado um conjunto de ações de comunicação para que todo funcionário compreenda bem as medidas e seus reflexos na gestão da Rede.

\subsubsection{Como funcionário se candidata}

Os candidatos, em relação aos perfis profissiográficos necessários ao exercício das funções, devem verificar se, no sistema, atendem ao perfil da função a qual pretendem ocupar, tendo assim, uma orientação do seu desenvolvimento profissional, indicando as competências que precisam ser aprimoradas ou desenvolvidas.

Os funcionários que atendem aos critérios estabelecidos poderão inscrever-se na oportunidade específica pelo próprio Sistema TAO Talentos e Oportunidades no aplicativo correspondente, no prefixo da Gestão de Pessoas de atendimento da dependência em que está lotado para registrar suas habilidades e competências. O candidato, ao inscrever-se na oportunidade, deve avaliar seu real interesse em concorrer à vaga. A desistência, sem devida exclusão da inscrição, traz prejuízo aos demais interessados e ao processo de ascensão na empresa.

\subsubsection{Avaliação da seleção}

Há uma combinação de metodologias e instrumentos da forma proposta no Programa com o objetivo de facilitar as escolhas do funcionário. As competências dos funcionários serão avaliadas de acordo com os parâmetros definidos no TAO, pelas provas de conhecimentos e por meio de avaliações técnico-comportamentais e entrevistas. Com os segmentos compostos pelos Módulos de Segmento Relacionamento e Segmento Serviços no Modelo Organizacional da Instituição de Rede Varejo, os cargos são organizados mediante o agrupamento de atividades afins, sob o ponto de vista do relacionamento e atendimento ao cliente, dos processos internos e das operações de suporte ao negócio.

Para a concorrências à qualquer cargo comissionado, os funcionários interessados deverão ter, no mínimo, dois anos de localização na atual dependência e comissão (sendo um ano referente ao prazo institucional e um ano referente ao prazo de relacionamento).

O Prazo institucional: 365 dias de permanência na comissão e/ou dependência, válido 
para todas as comissões do Banco; fundamenta-se na solução de continuidade dos serviços e reflete o compromisso mínimo com o cargo e a dependência.

Para Prazo de relacionamento: fundamenta-se na necessidade de estabelecimento de relacionamento duradouro e reflete o compromisso mínimo de permanência à frente do cargo que exerce. O prazo de permanência padrão ficou definido como de um ano, podendo ser modificado conforme as necessidades específicas de cada Diretoria ou Unidade.

Os funcionários classificados, na oportunidade, por prefixo de Gestão de Pessoas, serão convidados gradualmente para participarem da etapa, de acordo com as necessidades da organização.

A qualificação ocorrerá por meio de avaliação técnico-comportamental conduzida por colaboradores em Recrutamento e Seleção vinculados à Diretoria de Pessoas, em parceria com as diretorias gestoras dos pilares, ou por meio de entrevista conduzida por um comitê, formada por representantes da Diretoria de pessoas e diretorias gestoras dos pilares. O tipo de técnica a ser utilizada dependerá da função exercida pelo funcionário e da função para a qual pretende ser nomeado.

Os funcionários aprovados nessa etapa serão cadastrados como público preferencial para as concorrências a funções do segmento diretivo gerencial na rede, para as quais foi qualificado durante o período de cinco anos, respeitados os parâmetros das oportunidades.

Os funcionários não indicados na Qualificação deverão aguardar um ano para participar novamente desta etapa. Os candidatos continuam ocorrendo conforme disposto nos aplicativos de informação do Sistema.

Há uma fase de transição, após a realização da primeira edição do Programa, em que existem funcionários certificados e funcionários já qualificados, concorrendo com aqueles que ainda não obtiveram Certificação ou Qualificação. Os candidatos continuam obedecendo à relação dos vinte primeiros classificados, independentemente da condição do funcionário.

Visando o perfil de segmento, o gestor de pessoas visa desdobrar as competências em atitudes, conhecimentos e habilidades, esse trabalho é auxiliado pelo sistema TAO e em seguida, validado pelo Gestor detentor da vaga.
Concluindo a escolha do candidato, a instituição, no final do processo, considera a necessidade de retornar ao candidato, em feedback da avaliação; reunião com o requisitante da vaga para a apresentação do relatório final com os dados de cada participante do processo; indicação daqueles mais próximo ao perfil traçado e aos demais sugestões de aprimoramento para próximo processo de recrutamento interno.

\section{Conclusão}

O processo de recrutamento interno, seleção, treinamento e avaliação de seus candidatos contemplam uma das funções mais importantes de uma empresa, de buscar o colaborador adequado e motivar a busca de aprimoramento dos colaboradores, a fim de suprir as necessidades da empresa.

As empresas necessitam de funcionários capacitados para alcançar o almejado sucesso. Com essa visão, é necessário que a instituição tenha um Processo de recrutamento e seleção organizado, e com funcionários aptos a desempenhar o papel de recrutar, selecionar e treinar pessoas, tendo que o candidato selecionado estar realmente apto de acordo com o perfil de cargo e das necessidades da empresa.

A empresa precisa ter um planejamento sobre a realização do processo de recrutamento, seleção e treinamento, seja ele interno ou externo, para que a realização seja feita de maneira correta e adequada, para que, futuramente, a instituição não obtenha um problema em decorrência de falhas no processo.

Em visão do estudo, o processo Recrutamento Interno e Seleção da Instituição Financeira BB, utiliza ferramentas de uso diário para disponibilidade da vaga e candidatura de seus funcionários, quando os mesmos têm acesso às informações sobre a vaga disponibilizada e pode visualizar os cargos, suas competências e perfil, fazendo com os candidatos motivem-se a aprimorar seus conhecimentos e habilidades para conquistar a vaga preterida. A instituição segue a visão de alinhar seus interesses com os interesses de seus colaboradores, realizando assim um processo de recrutamento interno e seleção eficaz e eficiente.

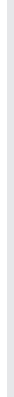


Uma possível sugestão seria o aprimoramento dos Gestores das instituições no quesito de melhoramento de seus conhecimentos na área de seleção e avaliação dos candidatos. Assim limitaria a probabilidade de falha no processo, sendo o mesmo um processo organizado e eficaz. Analisando o processo de recrutamento e seleção interna da Instituição

\section{Referências}

1. ANABB. BB implanta o Plano de Carreira e Remuneração. Acessado em 04 de Abril, 2011. <http://www.anabb.org. $\mathrm{br} /$ mostraPagina.asp? $\operatorname{codServico}=4 \& \operatorname{cod}$ Pagina $=42102>$

2. BANCO DO BRASIL. Acessado em 05 de Abril, 2011.

3. <http://www.bb.com.br/portalbb/ page 3,102,2681,0,0,1,6.bb?codigoNotici $\mathrm{a}=1508 \&$ codigoRet $=1208 \&$ bread $=1 \&$ co digoNoticia $=1504 \&$ codigoMenu $=616>$

4. BANOV, Márcia Regina. Recrutamento, seleção e Competências. São Paulo: Atlas 2010.

5. BERVIAN, P. A.; CERVO, A. L.; SILVA, $R$ da. Metodologia Científica. São Paulo: Pearson Education do Brasil, 2007.

6. CHAPMAN, Elwood N. Relações Humanas na Empresa - Desenvolvendo Habilidades Interpessoais. 1 ed. Rio de Janeiro: Qualitymark Editora, 1996.

7. CHIAVENATO, Idalberto. Recursos Humanos. 4. ed. São Paulo: Atlas, 1997.

8. Gestão de pessoas: o Novo papel dos recursos humanos nas organizações. Rio de Janeiro: Campus, 1999.

9. Como transformar RH (de um centro de despesas) em um centro de lucro. 2. ed. São Paulo. Makron Books, 2000.

10. Recursos Humanos. 7. Ed. São Paulo: Atlas, 2002.
Financeira escolhida, observou-se que a mesma possui um processo de seleção externa para início de carreira. Todavia, a Instituição Financeira BB, possui normas institucionais e um plano de carreira estruturado que visa o desenvolvimento dos seus profissionais, na busca contínua do aperfeiçoamento de suas habilidades, conhecimentos e atitudes.

11. Recursos Humanos. O capital humano nas organizações. 8. Ed. São Paulo: Atlas, 2004.

12. CHIAVENATO, Idalberto. Planejamento, recrutamento e seleção de pessoal: como agregar talentos à empresa. 7 . ed. Rev. E atual. - Barueri, São Paulo, 2009.

13. FENABAN. Revista Zap Empregos. Revisão de comissões gerencia Média. Acessado em 10 Março, 2011.

14. <http://www.zap.com.br/revista/ empregos/tag/fenaban/>

15. FISCHER, André Luiz; DUTRA, Joel Souza; AMORIM, Wilson Aparecido Costa de. Gestão de pessoas: práticas modernas e transformação na organizações / [organizadores] progep FIA. - São Paulo: Atlas, 2010.

16. FRANÇA, Ana Cristina Limongi. Práticas de Recursos Humanos - PRH : Conceitos, ferramentas e procedimentos. 1. ed. - 3 . reimpr. - São Paulo: Atlas, 2009.

17. MARRAS, Jean Pierre. Administração de Recursos Humanos: do operacional ao estratégico. São Paulo: Futura $-3^{\mathrm{a}}$ ed. 2000.

18. MILKOVICH, G. T.; BOUDREAU, J. W. Administração de recursos humanos. 8.ed. São Paulo: Atlas, 2000.

19. MINISTERIO DO TRABALHO E EMPREGO. Classificações de emprego e ocupações. Livro 1; Livro 2; Livro 3. Acessado em 04,05, 10 de Abril, 2011 e 20 e 21 de Maio, 2011. 
20. <http://www.mtecbo.gov.br/cbosite/ pages/downloads.jsf;jsessionid=F00FA F130AD0DBC3245DA0DCD32A4938. lbroute814\#>

21. MUCHA, Cleide Maria (autor); Ritter, Euzebio Luiz (co-autor). O atual plano de cargos e salários no quadro funcional do Banco do Brasil-Agências da Rede Palmitos (SC). Frederico Westphanlen-RS, 2003.

22. PASSOS, Soraya dos. Networking profissional: a percepção dos funcionários participantes do MBA em Gestão Financeira do Banco do Brasil sobre a influência das redes de relacionamentos nos processos de seleção interna. Porto Alegre, 2007.

23. PEREIRA, F. M.; PRIMI, R.; COBÊRO, C. Validade de testes utilizados em seleção de pessoal segundo recrutadores. Psicologia: Teoria e Prática. São Paulo, v. 5, n. 2, 2003. Disponível em <http:// www.scielo.bys-psi.org.br $>$. Acesso em: 16 mar. 2007.

24. PONTES, Benedito Rodrigues. Planejamento, recrutamento e seleção de pessoal. 5 ed. São Paulo: Ltr, 2008.
25. RIBEIRO, A. de L. Gestão de pessoas. São Paulo: Saraiva, 2005.

26. TACHIZAWA, Takeshy; FERREIRA, Victor Cláudio Paradela; FORTUNA, Antonio Alfredo Mello. Gestão com as pessoas: Uma abordagem aplicada às estratégias de negócios. 2 ed. Rio de Janeiro: Editora FGV, 2001.

27. VERGARA, Sylvia Constant. Gestão de pessoas. 3. ed. São Paulo: Atlas, 2003.

28. Projetos e relatórios de pesquisa em administração. Rio de Janeiro: Atlas. $10^{\mathrm{a}}$ ed. 2009.

29. SINDICATO DOS BANCÁRIOS. Sindicato tira dúvidas sobre o PCR - Conquistado pelos funcionários na campanha, plano contém avanços que precisam ser melhorados e levados a todos. 05 de Março, 2011.

30. <http://www.spbancarios.com.br/ download/bancos/cct_10_11.pdf $>$

31. SPECTOR, Paul E. Psicologia nas organizações. 2 ed. São Paulo: Editora Saraiva, 2002.

\section{Endereço para Correspondência:}

Fernanda Augusta de Oliveira Melo

fernanda.melo@foa.org.br

Centro Universitário de Volta Redonda - UniFOA

Campus Universitário Olezio Galotti

Av. Paulo Erley Abrantes, 1325

Três Poços - Volta Redonda - RJ

CEP: $27.240-560$

Informaç̃es bibliográficas:

Conforme a NBR 6023:2002 da Associação Brasileira de Normas Técnicas (ABNT), este texto científico publicado em periódico eletrônico deve ser citado da seguinte forma: MELO, Fernanda Augusta de Oliveira; REIS, Patrícia Nunes Costa; LIMA, Hyder Marcelo Araújo; RIBEIRO, Edson dos Santos; SILVA, Stifanie Paula da. A importância do recrutamento e seleção interna: Um estudo de caso em uma Instituição Financeira de Economia Mista. Cadernos UniFOA. Volta Redonda, Ano VI, n. 17, dezembro 2011. Disponivel em: $<$ http://www.unifoa.edu.br/cadernos/edicao/17/73.pdf $>$ 